\title{
The growing inaccessibility of science
}

Donald P. Hayes

That science has become more difficult for nonspecialists to understand is a truth universally acknowledged. Here is a measure of the extent of the process.

THERE is plenty of anecdotal evidence that large areas of the scientific literature are becoming incomprehensible to all but a few initiates. But how persuasive is anecdote? In this article I describe an objective way of looking at the matter and discuss its application to science journals over the past 145 years. The approach is a method for measuring text difficulty. The data are taken from articles describing research in four categories of publication: general science (Nature, Science and Scientific American); ten professional journals in astronomy, biology, chemistry, geology and physics; science textbooks for introductory college courses; and popular science magazines.

In a nutshell, the analyses confirm impressions that research papers are written for specialists. This style means that authors can be explicit in their referencing and economical with space. But whereas the approach produces succinct papers for editors and referees, it makes tough reading for nonspecialists.

In measuring the difficulty of a piece of writing each sample text is assigned a difficulty scale score based on its choice of words from the full English lexicon (see box). The higher the score the more difficult the text. The table indicates the scale's use, range and validity, and Fig. 1 shows the results of analysis of research articles in Nature and Science, and of articles in Scientific American, published between 1930 and 1990. Scientific American does not publish reports of original research, whereas the other two do.

For 125 years, between 1845 and 1970 , the use of vocabulary in Scientific American was at or slightly below the level of a modern newspaper (0.0); indeed, $S \mathrm{Ci}$ entific American, for its first 75 years, was a weekly newspaper of technology and science. Its language began to resemble that used in professional science journals after 1970. Interestingly, when the difficulty of the average article approached 15 , there was a decline of over 125,000 subscribers, implying that many readers found texts written at those levels too opaque. When the level of Scientific American later dropped towards 10 , there was a coincident increase in subscribers.

During Nature's first 78 years (1869 to 1947) it was not necessary to be trained in science to read its contents because they were written near the 0.0 level.

\section{RANGE OF LEXICAL DIFFICULTY IN SELECTED TEXT CATEGORIES}

Nature (article on the transhydrogenase reaction, 1960)

Science (abstracts of Report articles, 1990)

Cell (articles, 1990)

Nature (research articles, 1990)

Science (research articles, 1990)

Physics Today (articles, 1990)

New Scientist (articles, 1986)

This manuscript

International English-language newspapers $(N=30)$

Discover (popularized science, 1990)

Adult books, fiction, American

Ranger Rick (natural history

magazine for children)

Comic books, British and American

Childrens' books, fiction, British, age 10-14

Childrens' books, fiction,

American, age 9-12

Adult to adult conversations, casual

Mothers talking to their 31/4-yearold children

Farm workers talking to dairy cows

(Data from the Cornell University Corpus ${ }^{3}$.)

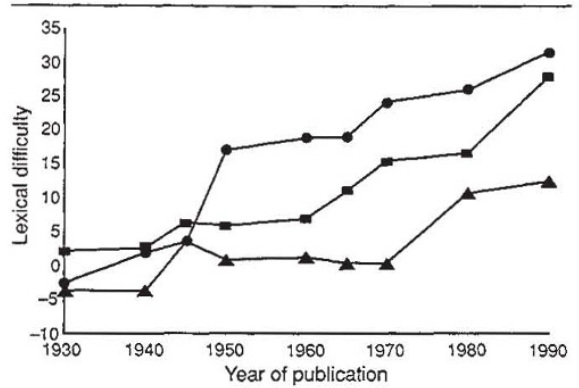

FIG. 1 The rise in lexicai difficulty in Nature $(\bullet)$, Science (घ) and Scientific American (\) between 1930 and 1990.

Nature became the first general science journal to show a change, and since 1947 its research articles have become harder to read in each successive decade. Science began, in 1883 , at -8.5 . In its first 77 years, the main articles remained at or slightly above newspaper levels. A change in the text difficulty in Science did not emerge until 1960 , but since then its articles too have grown much more difficult.

Although the impetus for this trend lies with research discoveries and theoretical developments, from the abruptness with which the changes in text difficulty occurred in all three publications it seems that editorial policy may have had something to do with it. Editorial policy affects how major articles and short reports are selected; how and for whom papers are written; and which fields in science are to be featured. One way in which the level of difficulty in Nature and Science changed was that fewer natural history papers were published (these are often descriptive and generally written at lower levels of difficulty), natural science papers (which are more analytical, and usually written at higher levels) being substituted instead.

What of the basic science journals? There too the trend is clear (Fig. 2). All ten of the journals analysed grew more difficult, and each was growing more difficult in every period between 1900 (or its founding) and 1990. There are few signs that the process is slowing.

The rates at which these journals changed and their most recent levels of difficulty, however, vary. For instance astronomy and physics journals are written at lower levels than those in biology, chemistry and geology. But because physics and related fields make the heaviest use of equations, their lower difficulty could well be an artefact - lexicographers do not consider equations to be words, and so exclude them from dictionaries and lexical analyses. Articles in biology, chemistry and geology, by contrast rely heavily on their exceptionally large technical lexicons to describe their complex and highly differentiated subject matter.

Coincidentally or not, major college textbooks for introductory physics $(0.1)$ and astronomy $(-6.5)$ were also written at lower levels than those for biology (4.5), chemistry (5.6) and geology (11.1). Equations were rare in all of those texts. Aside from the contribution formalizations make to text difficulty, every physics-related journal grew in lexical difficulty between 1950 and 1990: Astrophysical Journal rose from 3 to 18; Icarus, 10 to 21; Physical Review A, 6 to 17; Physical Review D, 10 to 15; and Journal of Geophysical Research, 7 to 16.

There are no doubt several contributory factors to science, as written, becoming tougher to understand. One of course is that scientific understanding has become ever more detailed. Another is the dynamics of publishing. Like fish 


\section{Text analysis}

ONE of the main contributors to a text's difficulty is its pattern of word choice. In English, this choice is from an estimated 600,000 word-types (terms having unique orthography). A lognormal model ${ }^{1}$ of word choice predicts that when the words from a large representative sample of texts are arrayed by the log of their frequency of use, the resulting cumulative distribution will be linear. British and US newspapers have closely followed this pattern of word choice since at least 1730. Because of this stability, the pattern's simplicity and their wide readership, newspapers were adopted as the standard for comparison.

Taking social interactions into account, however, leads to a more complex and general model. Speakers and authors normally tailor texts to their intended audience's interests and knowledge. Compared to newspaper word choice, texts of spontaneous speech underuse the more common grammatical words, overuse the more common substantive words and underuse the rarer substantive words, producing an S-shaped cumulative distribution. Difficult technical texts have the opposite biases, producing the reverse S-shaped distribution. Lexical difficulty is represented by this spectrum of lexical patterns.

The software used in the work described here calculates the discrepancy between a specific text's pattern of word choice and the linear pattern of newspapers. First, each text of $1,500+$ words is derived by multistage stratified simple random sampling and edited to a common standard. Second, a cumulative curve is generated from the words in that text beginning with the proportion of the most common English word, 'the'; to which is added the proportion of the second ('of'); the third ('and'); and so on through the 10,000 th most common word. (Reliable estimates for word frequencies beyond 10,000 are not available.) Third, the 75 most common words in English, accounting for about half the words in texts, are deleted as they contain little information.

Finally, the area beneath that text's cumulative curve is integrated and subtracted from the corresponding area beneath the cumulative curve for newspapers. Texts with negative lexical difficulty scores are skewed towards common words; those with positive scores are skewed towards rare words. The values quoted in this article represent the extent to which word choice is skewed relative to that of newspapers.

D.P.H.

1. Herdan, G. Language as Choice and Chance (Noordhoff, Groningen, 1956).

2. Carroll, J. B., Davies, P. \& Richman, B. Word

Frequency Book (Houghton Mifflin, Boston, 1971)

3. Hayes, D. P. J. Mem. Lang. 27, 572-585 (1988). on a reef, science magazines must compete for essential resources: important authors and papers, subscribers and, for some, advertisers. They may have to compete for or exploit lexical niches as well.

For example, in the late 1970 s it must have become apparent to other publishers that Scientific American had left its old niche at 0.0 and was not going to return. In the United States, four general science magazines were created to fill the gap. Science Digest transformed itself from a Readers' Digest format into a Scientific American lookalike (-2.6 in 1986). The American Chemical Society changed the name of the publication Chemistry to SciQuest, and broadened its message, coverage and appeal (2.2 in 1986). The American Association for the Advancement of Science (publisher of Science) developed Science-80 (-1.0 in 1986) to fill a void in part created when the research articles in Science had risen in difficulty from 7 in 1960 to 17 in 1980 . Only Discover survives $(-0.4$ in 1986 , but -3.6 in 1992). For a brief period, all four magazines occupied the 0.0 niche.

The growth of science has greatly enlarged the audience for general and technical science publications. As their technical articles became more difficult, the general science journals and magazines vacated their former lexical niches. These were soon filled (coincidentally at the vacated levels) by new publications or by ones which moved there from some other niche. Such publications now fill most niches between -22.6 and 38 . In particular, professional societies and science publishers have produced several single-science magazines tailored to specific audiences (for example Physics Today 13.3, BioScience 16.8, Geology Today 11.2, and Chemistry in Britain 12.6). There is even a chemistry newspaper, Reaction Times (7.8). A final adaptation to this trend has been for journals to differentiate parts of each issue, setting each section to a different lexical level, so all readers will find something they can read.

What, though, are the consequences of the drift towards inaccessibility? Specialization in science has produced unprecedented levels of knowledge, but the unwelcome side-effects are clear. These days, more expertise than ever is required to understand published research and theory in other fields and to referee papers and proposals in one's own discipline. The broad consequences are that ideas flow less freely across and within the sciences, and the public's access to (and maybe trust in) science is diminished.

To scientists this trend represents a narrowing of their range of expertise, even while the depth of their knowledge grows. So they may change specialities less often as the costs of becoming expert in another area grow. One response, I suspect, has been an increase in collaboration with scientists in other specialities. Another has been to develop still more complex research teams whose members have complementary skills and knowledge. Complicated sociological structures such as this can be productive but they introduce new kinds of tension, for instance disputes over the order in which names appear on a paper.

Projecting the trend summarized in Fig. 2, there will soon be basic science journals whose average article difficulty will exceed 40 , and before long some journal may consistently exceed 50 (indeed, many articles in Cell currently exceed 40, and a few now exceed 50). No mainstream science journal was as high as 10 in 1900. And of the nine journals examined and published as recently as 1950, only one was above 20 . This erection of higher and higher barriers to the comprehension of scientific affairs must surely diminish science itself. Above all, it is a threat to an essential characteristic of the endeavour - its openness to outside examination and appraisal.

Donald P. Hayes is in the Department of Sociology, Cornell University, Ithaca, New York 14853, USA. 